\title{
Students' Perceptions of Portfolio as a Motivating Factor in Learning English as a Foreign Language
}

\author{
Anita Muho \\ Klodiana Leka \\ Foreign Languages Department, \\ Aleksander Moisiu University, \\ 14, 2001, Rruga Currila, Durrës, Albania
}

DOI: https://doi.org/10.36941/jesr-2021-0127

\section{Abstract}

The goal of this study is to find out what students think about using a portfolio as a motivator tool in studying English as a foreign language. As they include both students' and teachers' viewpoints on the learning process, portfolios are viewed as potential assessment tools. This study made use of qualitative methods of research. We have used interviews, which was conducted with 70 students, in four high schools in Durres, Albania. Students' perceptions of utilizing portfolios as an assessment tool revealed that portfolios help students be more autonomous, promote critical thinking, and increase motivation. Portfolio is an effective assessment approach since it encourages students to improve in maturity and independence rather of simply exposing their flaws. Portfolio helps them to be critical thinkers and independent consequently motivating them in learning English as a foreign language. This study will assist teachers in using portfolios as an assessment tool to encourage students to learn English as a foreign language.

Keywords: Students' perceptions, portfolio, motivating factor, learn, English, foreign language

\section{Introduction}

Numerous political, social, and economic changes, as well as scientific and technological advancements, need constant changes in the educational system to help it adapt to the needs of the time. Changes in student assessment should be made to encourage effective assessment, which will drive students to learn a foreign language, for these changes to be sustained and adapted to European Union regulations.

Teachers, scholars, and educational systems have recently become interested in assessing student accomplishment. The relevance of assessment in the teaching and learning process is highlighted in this focus. Teachers have new obstacles in increasing student motivation, not just in terms of teaching, but also in terms of the assessment process. Changes in the assessment process at the school and classroom levels are required to assist students acquire knowledge, competences, and behavior.

The goal of this study is to find out what students think about using a portfolio as a motivator tool in studying English as a foreign language. Portfolios are regarded as excellent assessment tools 
since they feature both students' and instructors' perspectives on the learning process. Another important benefit of portfolio is that it differs from traditional techniques such as summative assessment or any standardized test as portfolios provide a continuous picture of a student's progress and they reflect their progress. (Herrera et al., 2007).

\section{Literature Review}

Black and William (1998b) determined the formative assessment as, "All of the actions that teachers and students engage in that provide data that will be used to adjust and improve teaching and learning activities." (p. 140). This definition is not limited to formal tests, quizzes, or homework, but is a collection of evidence about learning through practice, such as students' portfolio, selfassessment, peer assessment, and strategic questions. They define formative assessment as "Evidence gathered from assessments is used to adapt teaching methods and fulfill the needs of students." (Ibid, p. 140).

Popham (2008) also states that teachers and students can affect to change the teaching process. More specifically, it defines assessment in this way, "Assessment provides information about student achievement, which is used by teachers to improve their teaching practices." (p. 6).

In the above definition, we find three main components: evidence of students' knowledge, the nature of feedback given and improving teaching practices. These three key elements of formative assessment are also distinguished by Brookhart (2011), "Formative assessment: 1) collect information about teaching practices, 2) On the basis of the data gathered, instructional judgments are made, 3) help students based on their needs to improve." (p. 43).

Terry Crooks (1988), in a meta-analysis of studies on classroom assessment practices has summarized the results of 14 separate fields of research to clarify student achievement and the impact of classroom assessment practices. Crooks summarized the findings of his research on the impact of assessment on students. Classroom assessment, according to him, is an assessment based on activities that students participate in as part of their educational programs. These activities may include tasks such as formal tests designed by teachers, tests based on school curriculum (questions and other exercises as an integrated component of instructional materials), questions addressed to students, and a variety of other performance activities (cognitive and psychomotor)." (p. 467).

He has summarized his findings about the importance of assessment impact on the classroom and his students. Based on his research, he found that the assessment provide judgment about students in determining the most important information to learn, affects their motivation to learn, build the self-perception of their competence, helps them make decisions about what they seem to study, consolidates learning, and has an impact on the development of learning knowledge and strategies. "Assessment is one of the most significant elements that influence education." (p. 467), according to Crooks.

Brookhart (2007) investigated secondary school teachers' assessment procedures and student motivation; however, they did not look at the impact of formative assessment. Identifying deficiencies and correcting them are examples of formative assessment approaches that will assist students in meeting their learning objectives.

Further, Brookhart, Moss and Long study (2009), "The influence of assessment practices on students' learning achievement" has highlighted the findings of a five-year study, which was conducted in collaboration with the Armstrong School, in western Pennsylvania and the Center for Development of Teaching and learning, School of Education, University of Duquesne, in Pittsburgh, Pennsylvania. The study was based on formative assessment, communication teacher-student and students' ownership of the learning process, pointing out that formative assessment is closely related to students' intrinsic motivation and helps them to utilize their capacities, establish, and strengthen four important components of motivation for learning:

- Self-efficacy: students' confidence on their an individual's ability to participate in a 
particular circumstance.

- Self-regulation: students' role, as active participants in the learning process.

- Self-esteem: students analyze and judge their performance according to criteria and determine how they can improve it.

- Self-attribution: students' perceptions or explanations about success or failure, which determine the amount of effort that will be related to the goals.

As a result of research, findings of the above studies and the advantages that present formative assessment on the students' achievements and motivation, we have chosen to treat student portfolio as one of Formative assessment practices and identify its effect on student motivation for learning in learning English as a foreign language.

The concept of portfolio assessment is not new. Portfolios dated back in time as a collection of artists work and have been used to show students' competences. (Bintz, 1991). Portfolios have become a popular alternative as a means of transitioning from traditional to more authentic assessment practices. Mayer and Tusin (1999). According to William and Thompson (2008), aiming to collect their work help students show their effort, progress, and level of understanding for a period. But there is a change in using portfolios because they are more significant and useful due to their structure and content. Based on constructivist ideas, which believe that learners should design their own learning rather than being influenced by teachers, portfolios are highly useful for displaying students' work and demonstrating that the outcome is in line with learning objectives. (Steffe \& Gale, 1995).

Biggs (1998) stated that the preparation of portfolio is an active process that involves collecting, synthesizing, and organizing the content by providing evidence of achievement of learning targets; a process that necessitates ongoing assessment, reflection, and reasoning. It is believed that in preparing portfolio, students are motivated to reflect about their work, to figure out the learning needs and further encourage them (Harris, Dolan, and Fairbairn, 2001). To prove the importance of portfolio as an assessment practice, this hypothesis must be empirically tested.

Portfolios, according to Wiggins and McTighe (2007), "serve as a picture collection including distinctive photographs from distinctive times and places," as opposed to traditional assessment approaches that take a "photo" of students' work at a given moment. Furthermore, Herrera et al. (2007) believe that the content of portfolios displays a collection of students' works, and that "some prove how students learn on the method and how the result of his/her work met the set-up criteria").

Genesee and Upshur (1996) define a portfolio as a collection of works that illustrates their progress and successes to themselves and their peers. Student portfolios are used to keep track of the progress of students. Portfolios in foreign language can have a very specific focus that includes student's development in different aspects of language.

Genesee and Upshur sustain that the importance of portfolios consists in the assessment of student achievement. They are necessary because they ensure continuous evidence of students' language development which can be shared with others. They clearly state that assessing portfolio can foster the students' engagement and autonomy. Portfolios have positive impact because they allow students to participate actively in assessment and learning. According to Wiggin and McTighe (2007) the importance of using portfolios is first to establish their learning targets. A teacher selects what kind of student work to include, who should supervise it, and how often it should be checked. Teachers often instructed students to include essays, reflections, drawings, self-assessment, advance notes, videos, and sound samples in their assignments.

According to Belanoff (1994) portfolio increases student engagement and independence by allowing students to choose the work that will be assessed, reflect on their work, and revise it independently; take chances with their work and seek feedback from their peers as a result, rather than being a means of categorizing and finding weaknesses, assessment becomes a positive force that encourages progress, maturity, and autonomy.

Because they are created from classroom activities, portfolios are also a reflection of students' 
work; in most situations, they show "in-process modifications to instructional methods and evaluation," and they assess learning, which increases student motivation. (Herrera et al., 2007:32).

Gallagher (2001) also maintains that reflection is a vital component of portfolios because it allows students to learn from their experiences and practice, bridging the theory-practice division. Gallagher, also, stated that reflection not only helps students to identify the gaps in knowledge and competence, but also to confirm their strengths, skills, and knowledge.

\section{Methodology}

This study made use of qualitative methods of research, which are designed to understand students' perceptions about using portfolio as an assessment practice and its effect on their motivation to learn. To explore students' perceptions about portfolio as a motivating factor and to meet its goals based on findings of various studies about use of portfolio and motivation, this study has the following research objectives, which will be fulfill by the relevant research questions.

Objective 1: To identify students' perceptions about using portfolio in foreign language acquisition.

Objective 2: To identify it there is a link between using portfolio as an assessment tool and its effect on motivation for learning in acquiring a foreign language.

The following research questions were posed to address the research objectives:

Research question 1: How do students consider the implementation of a portfolio in motivating them to learn English as a foreign language?

Research question 2: How does portfolio enhance student motivation in acquiring a foreign language?

\subsection{Participants}

The study's demographic was high school students in the 2020-2021 school year. We utilized intentional and convenience sampling since they are the greatest fit for the qualitative nature of our investigation. The sampling was 70 students in four high schools of Durres, Albania.

\subsubsection{Students' distribution by gender}

Regarding the students' distribution into male and female, the graph below shows that most of students $62.1 \%$ are girls, while boys are $37.9 \%$, referring to the rapport of the population, which is dominated by women.

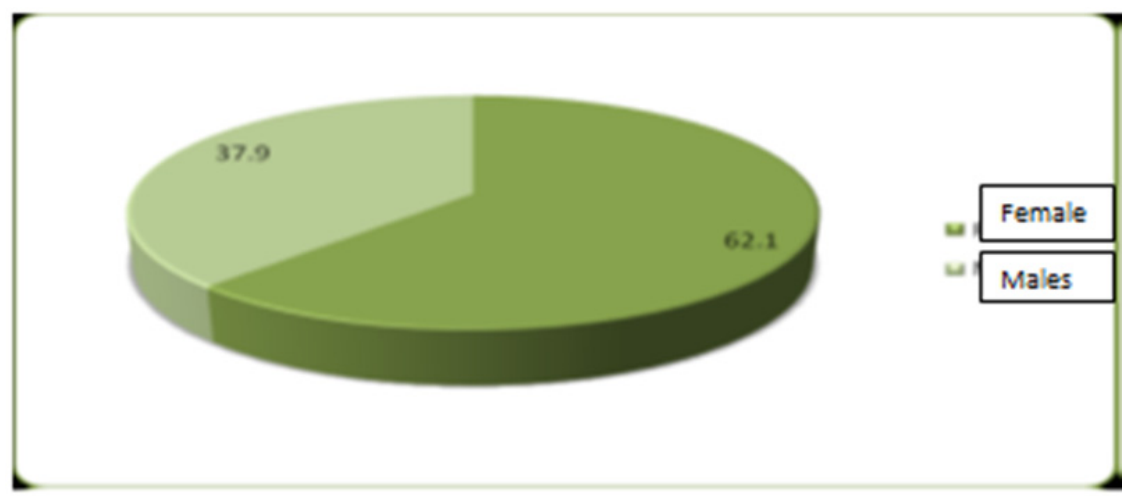

Graph 1: Students' distribution by gender 


\subsubsection{Students' distribution by age}

Regarding their age, it is noted that the minimum age of participants in this study (students) is 14year-old and maximum is 19-year-old, while the average age is 17-year-old. (Table 1)

Table 1: Students' distribution by age

\begin{tabular}{|l|c|c|c|c|c|c|}
\hline & Number & Minimum age & Maximum Age & Average Age & Standard deviation & Variance \\
\hline Age & 1100 & 14 & 19 & 16.8 & 92 & 86 \\
\hline
\end{tabular}

\subsubsection{Time spent by students to study in a week}

Students were asked about the average time they spend to study a second language, in a week. The responses were: $44.7 \%$ of them spent less than 6 hours, while most of students $86 \%$, studied in public schools, followed by $39.7 \%$ who responded that they spent 6-15 hours a week and the rest $15.5 \%$, spent more than 20 hours a week (Graph 2).

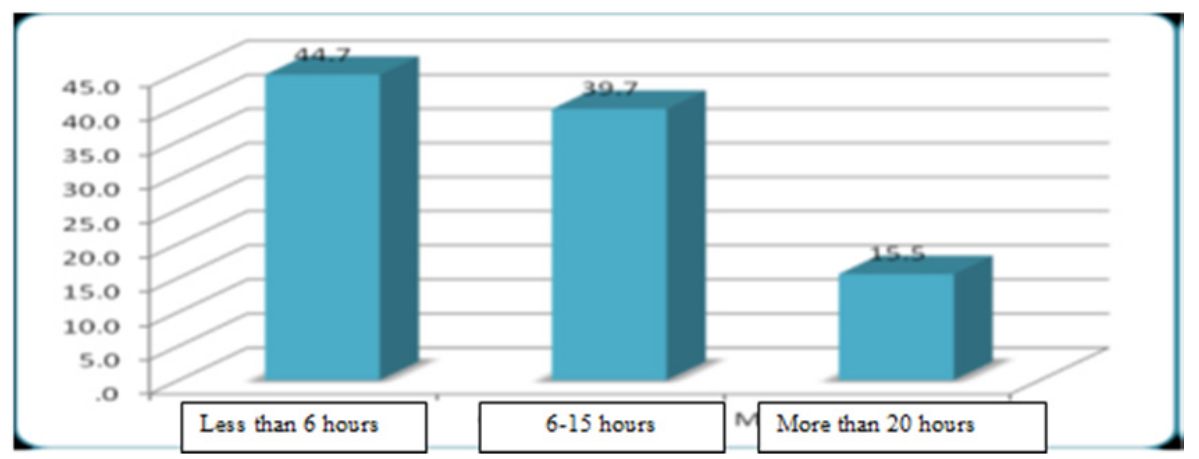

Graph 2: The average time spent to study in a week

\subsection{Data collection}

The process of data collection was coordinated with the permission of the Regional Education Directorate of Durres. Due to Covid-19 restrictions data collection lasted about 3 months (OctoberDecember 2020). The data collection method in this study was an in-depth semi-structured interview, to explore their perceptions regarding assessment practices in learning English as a foreign language. There were used in-depth semi-structured interviews to enable bilaterally focus and communication. They were held after school, on-school premises and data collection followed a guide interview, which made the interview process a little more structured. Interview questions were developed based mainly on literature review findings. The interview lasted an hour. With the consent of the students interviewed were used recording devices during the interview process to ensure the most detailed information. The transcript of each interview was conducted immediately after the interview. Initially, the interview began with some questions about participants' demographic elements, to continue with questions, which were related to the research issue.

\subsection{Data analysis}

The interviews were recorded and transcript. Interview transcription enabled the data to be correctly formatted. Data analysis was based on descriptive reports of each interview. The method used for 
data analysis in this study, was thematic analysis method. Data analysis based on this method was carried out under the following phases:

- Familiarity with interview contents by reading the descriptive reports of each interview.

- Identify specific thematic strands, reports of interviews.

- Organize topics into categories, depending on their content: the definition of the categories and subcategories.

- Encryption of data through the categories and subcategories putting notes near paragraphs that express the same themes in interview reports.

- Finally, each part of the interview was coded in written reports and grouped according to the main category and sub-categories.

\subsection{Ethical considerations in data collection}

The compliance of these ethical principles became one of the most significant issues of this study to encompass all participants in the study. Clarifying the aim of the study was one of the main elements of the study, which was done to avoid misinterpretations that might arise.

In this study, several steps had been taken to assure that all ethical standards can be realized appropriately throughout the process.

- Before the data collection, it was asked the permission of Regional Education Directorates of the cities, where the study was undertaken.

- Before interview, it was made clear the research aim, the voluntary nature of participation in the study and the possibility of withdrawal from it if they had no desire to participate in it.

- Participants were familiar with the fact that all this information would be used only for research purposes.

- During interviews it was respected the right of students not to respond when they were reluctant to speak and, in all cases, respecting the right of voluntary participation in the study.

- The students interviewed were assured their anonymity by not making known the identity of them at any time and for any reason.

- All the data used in this study were kept strictly confidential.

- All data were carefully labeled to keep everything safe.

\subsection{Study Limitations}

The objectives of this study were to identify students' perceptions about using portfolio in foreign language acquisition and to identify if there is a link between using portfolio as an assessment tool and its effect on motivation for learning in acquiring a foreign language, but it is necessary to point out that this study had some limitations, which were:

The Sample: In the initial draft, this study was considered to use a more representative sample, by using schools in different cities of Albania but due to time and cost, it was focused only in four schools in Durres, Albania.

Study context: All efforts were made to encourage honest answers by preserving anonymity and privacy. However, the fact that the interviews were carried out in the school may had influenced their responses.

\subsection{Findings}

3.6.1 Objective 1:

To identify students' perceptions about using portfolio in foreign language acquisition.

Research question 1: How do students consider the implementation of a portfolio in motivating them 
to learn English as a foreign language?

To get information about students' perceptions about the use of portfolio as a means of assessment, first the students were asked if they use it - Do your teachers use portfolios as an assessment practice? - $65.7 \%$ of students responded positively and the majority of them came from public schools $87.1 \%$, another significant number of students $34.3 \%$ responded that teachers do not use student portfolios, $75.6 \%$ of them came from public schools and the rest $24.4 \%$ from non-public schools (Graph.1).

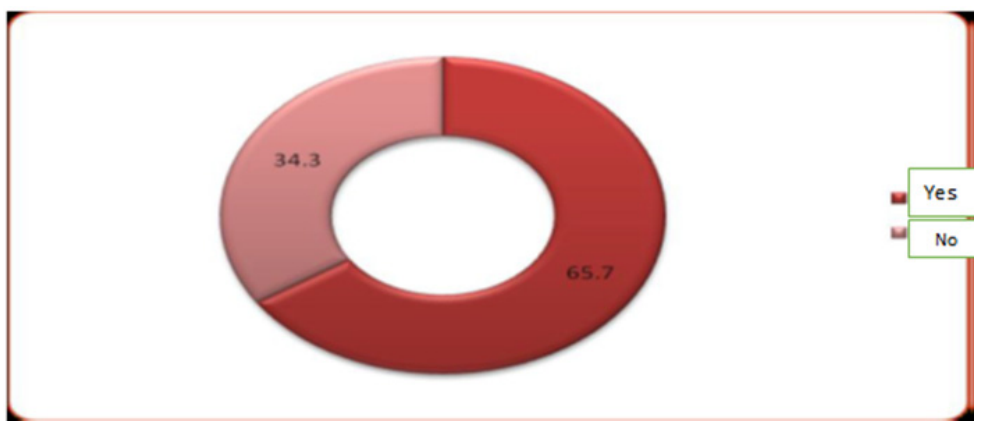

Graph 3: Students' portfolio as an assessment practice

Students who responded positively in relation to the use of students' portfolio, were further asked about their perceptions about its use as an effective assessment practice. They answered - I like the use portfolio for my assessment, with $65.7 \%$, followed by - Teachers' instructions about portfolio completion have helped me recognize my strengthens and weaknesses- with $63.1 \%$ and $58 \%$ for the statement - When I complete the portfolio, I think about the final result. These three statements are all linked to students' portfolios as a kind of assessment. Other statements are made after them. - Portfolio as a form of assessment has transformed the way I think about problems. -with 53.3\%, -Portfolio has helped me being independent- with 52\%, -During portfolio completion, I think about the task- with 50.6\%.

While $\mathbf{2 7 . 7} \%$ and $24.5 \%$-Completing the portfolio is a difficult process for me- and -The teacher does not give us enough guidance materials (tasks) that we need-. Other values are shared between responses disagree and strongly disagree, while the neutral responses range from $10 \%-24 \%$ of the responses.

\subsubsection{Objective 2:}

To identify it there is a link between using portfolio as an assessment tool and its effect on motivation for learning in acquiring a foreign language.

Research question 2 : How does portfolio enhance student motivation in acquiring a foreign language?

Qualitative data analysis about students' portfolio and its priorities as a motivating factor in learning English as a foreign language identified four following categories.

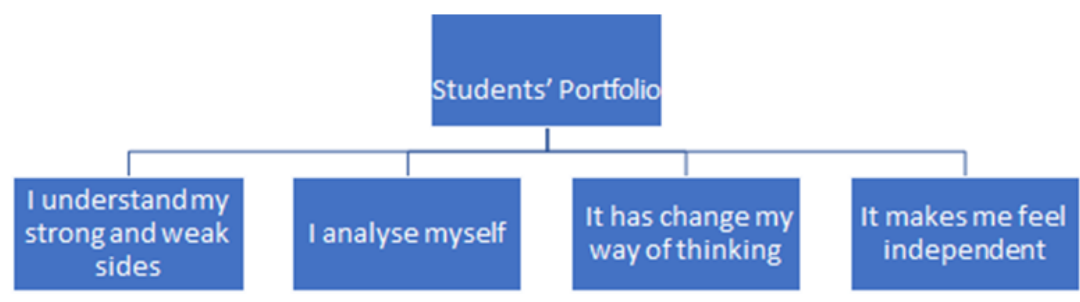


1. I know my strong and weak points.

2. I have changed my way of thinking.

3. Self- analyzing

4. Self-independence

Portfolio helps me understand my strong and weak points; I also understand where I should work hard to improve my English. (M.L, student, 16-year-old)

Our teacher uses portfolio to assess us and shares the assessment criteria with us. Portfolio has influenced the way I look about and analyze my success in this discipline. It also allows me to learn from my own experience and practice, bridging the theoretical and practical barrier. (S.K, student, 17 years old)

We often use portfolio as an assessment practice and our teacher instructs us in what we shall include in the portfolio. Portfolio assessment helps me in self-analyzing, understanding learning targets and how to achieve them. ( E.M, student, 15-year-old)

Portfolio helps me to fulfil the task in which I will be assessed, reflect about it, and I have under control my learning performance in this subject. Portfolio makes me feel independent in second language. (K.D student, 18-year-old )

\section{Discussions}

Students' perception about the portfolio assessment resulted that they prefer the portfolio for their self- assessment. Teacher's instruction about portfolio usage helps them to understand their weak and strong points. During the portfolio completion, students think about the final assessment.

Students did also claim that portfolio assessment have changed the way of thinking in affronting problems, whereas the portfolio itself helps them being independent. During the portfolio completion, students think also about the task.

Qualitative data analysis about students' portfolio and its priorities in assessment in second language class, emphasized 4 categories:

- Portfolio helps to identify students' strong and weak points.

- Portfolio has changed students' way of thinking.

- Portfolio enhances their self- analyzing

- Portfolio boots their self-independence

Students' perceptions of adopting portfolios as an assessment practice revealed that portfolios assist students in becoming more autonomous, promote critical thinking, and increase their performance. Harris, Dolan, and Fairbairn (2001) came to similar conclusions, stating that using a portfolio encourages students.

Belanoff (1994) also affirms that portfolio as an assessment practice prompts students' independence and promotes their engagement and autonomy. Portfolios assist people in reflecting on their work, selecting the work for assessment, redefining and improving their work, taking on new challenges in the writing process, and seeking input from peers. As we can see assessment is a positive factor, which prompts students' improvement, maturity, and independence it is not a tool to show their weakness. (Belanoff 1994, p.35)

\section{Conclusions}

The objectives of this research were to find out what students thought about utilizing portfolios in foreign language acquisition and to see if there was a link between using them as an assessment tool and motivation to learn a foreign language. The results of the interviews with the students offered evidence of the impact of the portfolio on student motivation to learn. 
The findings of the study back up the idea that a portfolio can help students become more motivated to learn a foreign language. However, it is important to note that these beneficial outcomes would not be possible if the portfolio was simply used to collect students' work. The portfolio process has four components that should be combined to make portfolio a motivating tool; First, portfolio helps to identify students strong and weak points in their learning process. Second, Portfolio contribute to help them became critical thinkers. Third, Portfolio enhances their selfanalyzing. Fourth, using portfolio boots student self-independence.

When students meet diverse issues during the learning process, a portfolio can help them think differently, as well as improve critical thinking through reflection. Self-analysis is the ability to evaluate one's own work, which improves learning and motivation. Furthermore, the study discovered that students require a particular amount of time to build self-analysis skills while using the portfolio approach. As individuals become more accustomed to self-analysis, they recognize the advantages of employing portfolio. Based on the findings of this study, students at the beginning of using portfolio were dependent on teachers' instructions but using it further helps them become independent. Thus, as they looked at their learning development critically, they started to take control on their learning.

To summarize, portfolio is an efficient assessment practice because it promotes improvement, maturity, and independence and it is not just a tool to expose the shortcomings of the students.

Portfolio helps them to be critical thinkers and independent consequently motivating them in learning English as a foreign language. This study will contribute to help teachers using portfolio as an assessment practice to motivate their students in learning English as a foreign language.

\section{Study Implications}

This study on students' portfolio as a motivating tool in acquiring a foreign language shed light on some implications and further studies on using assessment practices as motivating factors.

\subsection{Recommendations for education policymakers and schools and foreign language teachers}

1. Organizing trainings for foreign language teachers which include assessment practices as a motivating factor, to help them in expanding their knowledge on major principles of formative assessment: such as portfolio, peer assessment, self-assessment etc.

2. Enabling methodical publishing for teachers, including assessment practices and their effects on students' motivation and strategies for their management.

3. Revising the assessment component on the schools' curriculum.

4. Based on the outcomes of this study, it is suggested that portfolio be promoted and used more effectively.

5. It is recommended the use assessment practices like portfolio to boots student motivation for learning.

6. It is recommended descriptive and explanatory feedback in assessing students work.

\subsection{Further recommendations}

Further research could be undertaken based on the findings and conclusions of this study, as well as the gap in studies in formative assessment practices on student motivation for learning a foreign language in the Albanian context.

1. An experimental study could be conducted to find evidence on the effects of portfolio in student motivation, by training teachers previously on formative assessment practices.

2. Experimental or quasi-experimental studies could be conducted to find evidence on the effects of different practices of formative assessment on student motivation for learning in acquiring a foreign language. 


\section{References}

Barton, J., \& Collins, A. (1993). Portfolios in teacher education. Journal of Teacher Education 44: 200-10

Belanoff, J. (1994). How a teacher's beliefs and knowledge inform practice. National Association for Research in Science Teaching. Atlanta, Giorgia.

Biggs, J. (1998). Assessment and classroom learning: A role for summative assessment. Assessment in Education, 103-110

Bintz, D. (1991). Pre-emptive formative assessment. Hong Kong: University of Hong Kong.

Black, P. \& Wiliam, D. (1998). Assessment and classroom learning. Assessment in Education 5, 7-74.

Black, P. \& Wiliam, D. (1998b). Inside the black box: Raising standards through classroom assessment. Phi Delta Kappan, , 139-148.

Brookhart, S. M. (2007). Formative classroom assessment: Theory into practice (43-62). New York: Teachers College Press.

Brookhart, S. M. (2011). Educational assessment knowledge and skills for teachers. Educational Measurement: Issues and Practice, 3-12.

Brookhart, S. M., Moss, C. M., \& Long, B.A. (2009). Promoting student oWnership of learning through highimpact formative assessment practices. Journal of MultiDisciplinary Evaluation. 6 (12), 52-67.

Crooks, T. J. (1988). The impact of classroom evaluation practices on students. Review of educational research, 58(4), 438-481.

Harris, M., Dolan, J., \& Fairbairn, J. (2001). From evidence to action: A seamless process in formative assessment? Educational Measurement. Issues and Practice, 28(3), 24-31.

Gallagher, S. (2001). The practice of mind. Theory, simulation or primary interaction?. Journal of consciousness studies, 8(5-6), 83-108.

Genesee, F., \& Upshur, J. A. (1996). Classroom-based evaluation in second language education. Cambridge University Press.

Mayer, N., \& Tusin, E. (1999). "Promoting motivational goals through alternative or traditional assessment". Studies in Educational Evaluation,28, 199 - 222.

McCaslin, M. (2004). Co-regulation of opportunity, activity, and identity in student motivation: Elaborations of Vygotskian Themes. In D. M. McInerneyESS. Van Etten (Eds.), Big theories revisited: Research. GreenWich: CT: Information Age Publishing.

McManus, S. M. (2008). A study of formative assessment and high stakes testing: Issues of student efficacy and teacher views in the mathematics classroom. North Carolina State University.

McTighe, J., \& Wiggins, G. (2007). Schooling by design. Alexandria: ASCD.

McTighe, J. \& K. O'Connor. (2005). Seven practices for effective teaching. Educational Leadership 63 (3), $10-17$.

Musai, B. (2002). Metodologji e Mësimdhënies. Tiranë: Pegi.

Pintrich, P. R., \& Schunk, D. H. (2002). Motivation in education: Theory, research, and applications (2nd ed.). Upper Saddle River, NJ: Merrill/Prentice-Hall.

Popham, W. J. (2008). Transformative assessment. Alexandria: VA: ASCD.

Reinert, M. (1992). Balancing self-esteem and rigorous academic standards. English Journal, 81 (3), 74-81.

Rueda, R. \& Chen, C. B. (2005). Assessing motivational factors in foreign language learning: cultural variation in key constructs. Educational Assessment, 10 (3), 209-299.

Sadler, D. R. (1983). Evaluation and the improvement of academic learning. Journal of Higher Education, 54, 6o-79.

Sadler, D. R. (1989). Formative assessment and the design of instructional systems. Instructional Science, 18, 119-144.

Schmidt, R. \& Watanabe, Y. (2002). Motivation strategy use and pedagogical preferences in foreign language learning. In Dörnyei, Z. ESchmidt, R. (eds.). Motivation and Second Language Acquisition (313-359). Honolulu, Hawaii, USA: University of Hawai Press.

Schmidt, R., Boraie, D. \& Kassabgy, O. (1996). Foreign language motivation: Internal structure and external connections. In Oxford, R. (ed.). Language Learning Motivation: Pathways to the New Century (Technical Report No. 11, 9-70). Honolulu: University of Hawaii, Second Language Teaching \& Curriculum Center.

Schunk, D. H. (1991). Self-efficacy and academic motivation. Educational psychologist, 26(3-4), $207-231$.

Schunk, D. H. (200o). Coming to terms with motivation constructs. Contemporary Educational Psychology, 25, 116-119.

Steffe, S.S. \& Gale, E. (1995). “Teacher evaluation: The limits of looking”. Educational Researcher. 13(9), 11-18.

Stiggins, R., \& Chappuis, J. (2006). What a difference a word makes: Assessment "for" learning rather than assessment "of" learning helps students succeed. Journal of Staff Development, 27(1), 10-14.

William, D., \& Thompson, M. (2008). Integrating assessment with learning: What will it take to make it work?. (53-82). New York.

Zimmerman, B. J. (200o). Attaining self-regulation: A social cognitive perspective. In M. Boekaerts, P. R. Pintrich, \& M. Zeidner (Eds.), Handbook of self-regulation (13-39). San Diego: Academic Press. 